\title{
Finite element analysis for palm oil bunches press shaft fractured in service
}

\author{
O. Bohórquez ${ }^{1, a}$, S. Ardila ${ }^{1, b}$ A. Pertuz ${ }^{1, c}$, O. A. González-Estrada ${ }^{1, d}$ \\ ${ }^{1}$ GIEMA, School of Mechanical Engineering, Universidad Industrial de Santander \\ Bucaramanga, Colombia \\ åoscar2168906@correo.uis.edu.co, ${ }^{\text {b}}$ sergio.ardila9@correo.uis.edu.co, 'apertuzc@uis.edu.co, \\ dagonzale@uis.edu.co
}

Keywords: fracture in service, FEM, fruit bunch press, shaft, failure mode.

\begin{abstract}
In this work, the behavior of a palm fruit bunch press shaft is investigated, which has presented early failure several times, not reaching its expected lifetime. The study developed allows determining the failure mode of the shaft by using the finite element method (FEM). In the model, was estimate the load produced by the fruit bunches over the worm screw and transferred to the shaft. Geometrical analysis of the shaft shape helps to determine failure mode. The stress and strain fields are obtained to determine the critical points of the design, allowing suggesting several forms to correct damage in the future. Moreover, after a short time of operation, the structure presented wear; the hexagonal shape in the shaft is fixed using a welding procedure. Is showed metallographic and hardness results obtained on surface and subsurface level of the affected area for the fractographic analysis. This is compared with a raw steel SAE AISI 4340 under tempered like original condition.
\end{abstract}

Introduction. Colombia is the fourth palm oil producer in the world, palm oil industry represents in Colombia $4.2 \%$ in farming industry volume with half million of hectare in the country[1], in this process, bunches of palm are impregnated with oil by sterilization cycle and fruit removal operation. the recovery of this oil represents until $2.11 \%$ of palm oil rate extraction[2], a strategy for this saving is take bunches and pass them for an additional pressing stage, this equipment for pressing has constituted by one motor, a gear reducer for speed reduction and torque increasing, coupling unit, and a unique body of press, that contains a drilled cage, three helical sections with rising diameter, and a principal shaft that support and distribute the force represented in torque to crush bunches[3]. A local manufacturer of this press, developed a new model applying a shape variation in shaft, bring on a hexagonal profile in the transversal section, the equipment showed a premature failure in service, giving an opportunity under FEM type review to analysis this geometry and his stresses and strains, while metallographic tests are applied with purpose to value real condition. A 3D model of this shaft configuration is showed in figure 1.

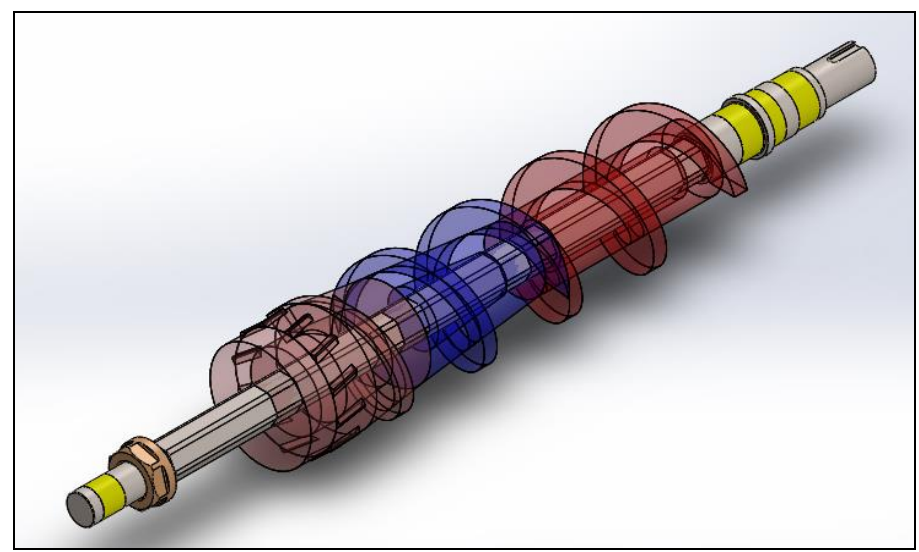

Fig. 1 Shaft CAD model in palm oil bunches press 
This model presented a premature wear in support zone where hexagonal area in shaft convey torque to helical sections, specifically in the more restricted area zone, this let that these helical section slide above the shaft. After this failure mode, it was realized a welding procedure to reconstruct the shaft, hexagonal faces were not repair with a precision measures, causing a nucleation of crack to finally, obtain a fracture on shaft. Figure 2 shows images of shaft, with wear, and after of repair, and fracture final shaft.

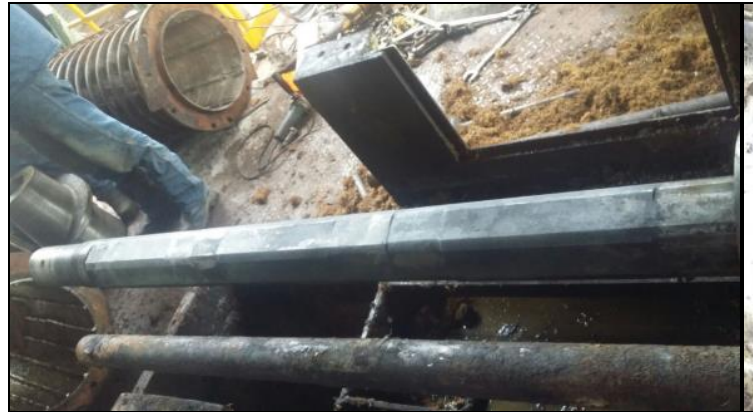

(a)

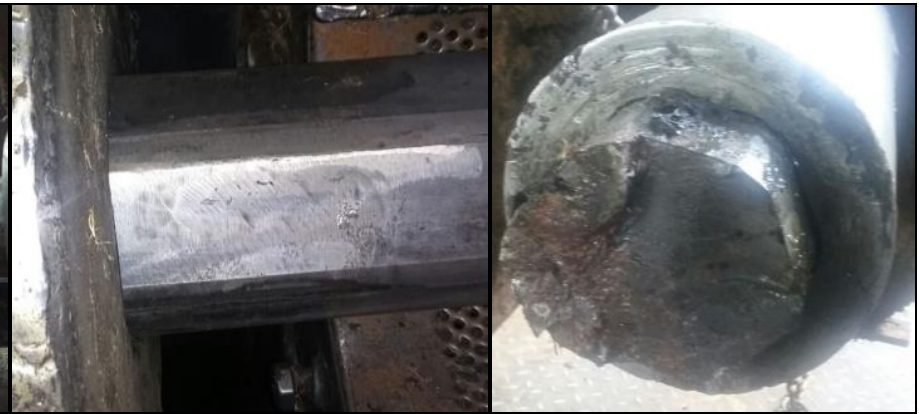

(b)

(c)

Fig. 2. Weared off shaft (a), repaired shaft (b), fractured shaft (c).

\section{Methodological Framework.}

Structural analysis by finite elements method (FEM). An estimation is made of the field of stresses and deformations to which the shaft is subjected, taking as reference the energy consumption data provided by the process. These fields allow predicting the failure mode of the component, and in this way determining the causes that could produce this event characterized by a strong wear due to plastic deformation of the material that forms the hexagonal shape and that serves as support for the helical sections.

Problem statement. Numerical method was developed using 3D model from assembly, for problem solution was considered a AISI/SAE Steel 4340 bonified, with Young's modulus $\mathrm{E}=200 \mathrm{GPa}$, and Poisson's ratio $v=0.3$. Operational torque was calculated using voltage $220(\mathrm{~V})$ and current 244(amp), data collected in workplace and applying reduction due to mechanical mounting and motor efficiency.

$$
\mathrm{P}_{\text {shaft }}=\mathrm{P}_{\text {electrical }} * \eta \text { motor } * \eta \text { mounting. }
$$

This power gives a reference about the torque value under power mechanics equation[4], taking the rotational speed directly on shaft $16(\mathrm{rpm})$, and considering reduction ratio by gearbox, effective torque was calculated in $34893\left(\mathrm{~N}^{*} \mathrm{~m}\right)$.

$$
\mathrm{P}_{\text {shaft }}=\mathrm{T}_{\text {shaft }} * \mathrm{~N}_{\text {shaft }} \text {. }
$$

Boundary conditions. Shaft is supported by three rolling bearing, those preserve linearity and rotation on himself, due to working mode. This condition presents the model like a cylindrical support, giving restriction on moving in axial and radial direction. Figure 3 shows these conditions in the mounting system, where axial displacements are restricted by the cage and body of press. 


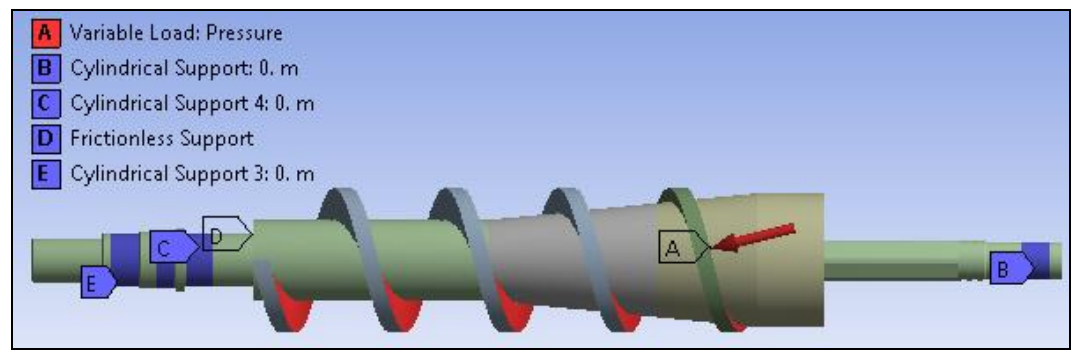

Fig. 3 Boundary conditions in shaft.

Finally a normal variable pressure was instaured in length of helical surface, this represents the force by bunches of palm oil compressing in the equipment. The pressure was calculated considering the energy consumption, obtaining in this mode the typical torques on working regimen of press[5]; to calculate the compacting pressure a numerical method was used, the input variable was the pressure in helical section, and output variable was operational torque on shaft, then making several iterations, a pressure profile was found as result by static equilibrium, applied on the helix above the shaft, this pressure flows from 0 to $9(\mathrm{MPa})$ in $\mathrm{x}$ axis direction, Top value was located in the highest transversal area, a lineal simplified model on load distribution was assumed. This consideration represents a low friction model. These considerations are showed in figure 4 .

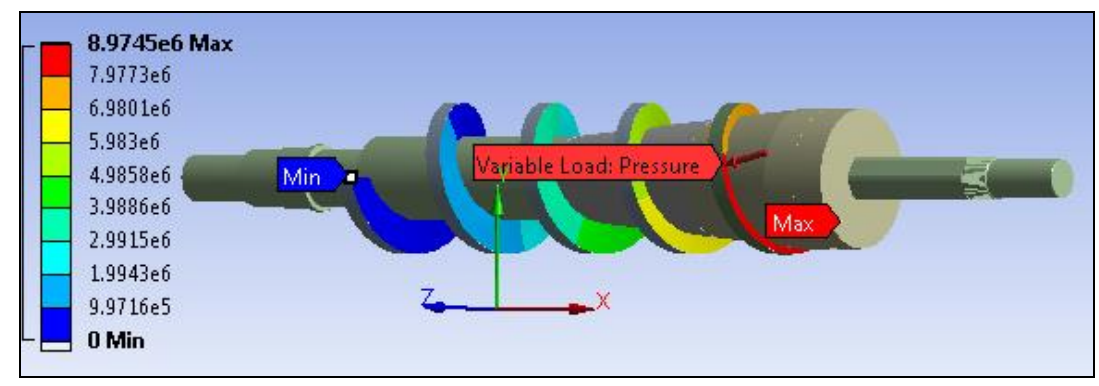

Fig. 4. Pressure load profile in shaft.

To analyzed the shaft was considered a Bonded type contact between helicoidal sections and shaft, reducing relative moves, and Frictionless type contact between final faces in helicoidal parts, this condition let tangential displacements con friction coefficient equal to zero[5]. Mesh type used in simulation is formed by quadratic tetraedrical elements SOLID187 type. In the beginning, level 2 adaptative meshing was used in strain concentrator, located in the sectional change area. Due to torque level, weight from elements was negligible, numerical tries showed low variations almost $0.4 \%$ of maximum stress with these values considerate.

Metallographic analysis. Fracture zone was cut to obtained specimens to analyze under microscope, and verify conditions of hardness and grain formations at initial condition of shaft material and due to welding procedure affectations. These test were lined to ASTM E-3 and ASTM E-18, and finally ASTM E-407

\section{Results.}

Computational modelling. Von Mises strains are showed in figure 5. Can be observed that maximum strain is $823(\mathrm{MPa})$, which is higher than elastic limit of material of shaft, $710(\mathrm{MPa})$. This value let verify the plastics deformations showed in mechanical element [4]. This shape shows 
singularity conditions for hexagonal borders, these configuration presents several points where undefined load is located, additional to these models, the mechanical adjustment between helical sections and shaft, with hexagonal faces both of them, can to focus on this area, causing multiple stresses concentrator generation on depends of this adjustment.

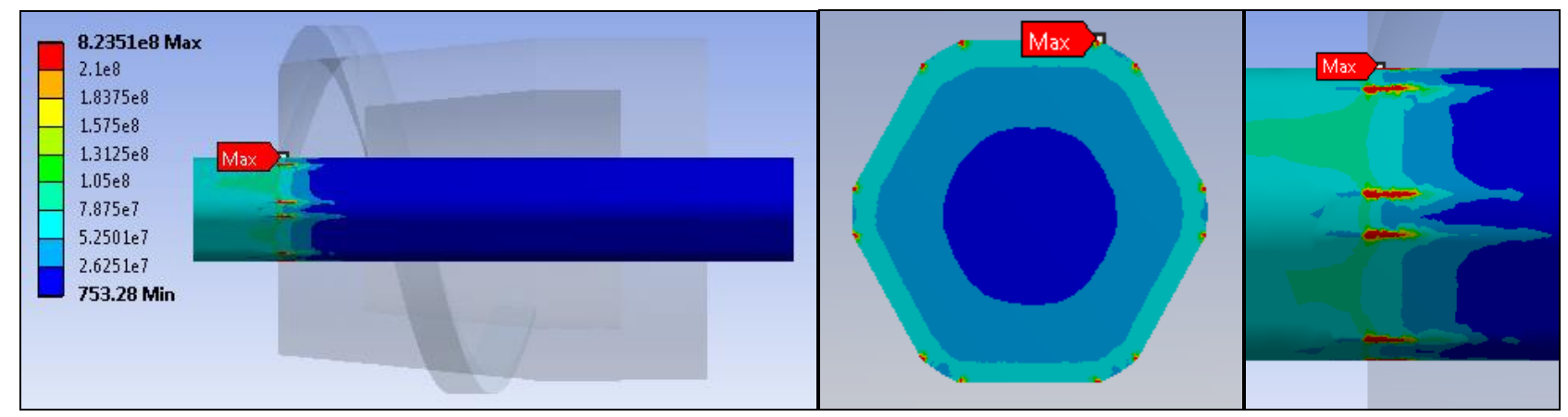

Fig. 5. Von Mises stresses state on shaft.

To obtain these results was realized located refining level 2 and adaptative refining on area of interest, with maximum range of $5 \%$ for this solution in displacements. Table 1 shows convergence values to independence of meshing.

\begin{tabular}{cccc}
\hline Nodes. & Elements. & $\begin{array}{c}\text { Max. total } \\
\text { displacements. }\end{array}$ & $\begin{array}{c}\% \\
\text { Variation. }\end{array}$ \\
\hline 68011 & 45278 & $8.85 \mathrm{E}-05$ & \\
123180 & 85018 & $8.74 \mathrm{E}-05$ & -1.17 \\
\hline
\end{tabular}

Table 1. Meshing convergence

Metallographic results. Specimens preparation was based in ASTM E-3 and microstructural analysis was based in ASTM E-407; figure 6, shows microstructures of material previously to welding procedure to repair the shaft, martensitic tempered structure is predominant clearly.

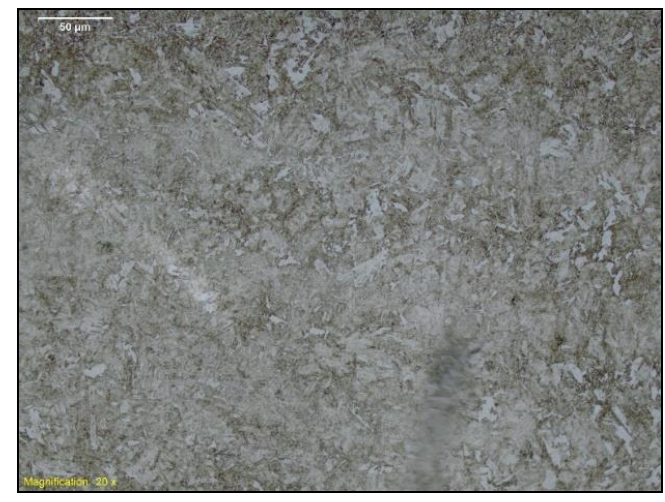

(a)

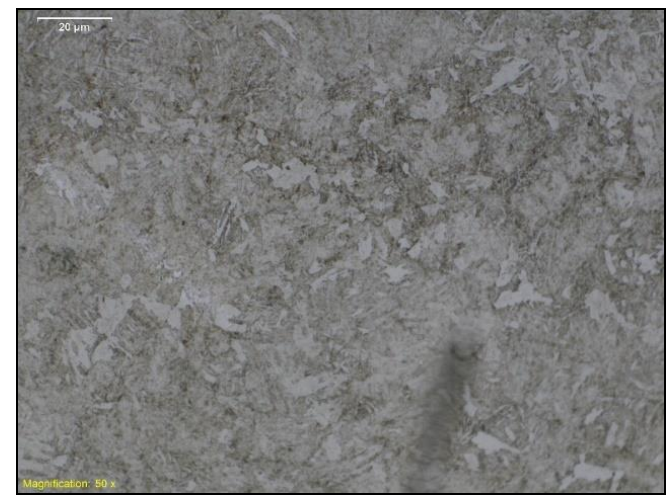

(b)

Fig. 6. AISI Steel 4340 bonified, microstructure previous to repair procedure, microetching with nital 3\%, martensitic tempered microstructure (a) 200X, (b) 500X 
Figure 7 presents a metallographic structure of transversal section on repaired zone, under a welding procedure, a microstructural change between this and image from shaft without intervention, let shows a ferritic and pearlitic structure, and low martensitic structure scattered. This formation is caused by heat treatment originate in welding process.

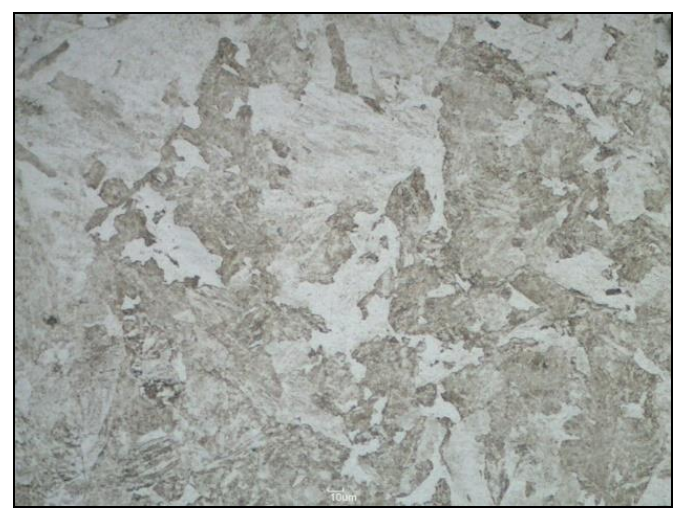

(a)

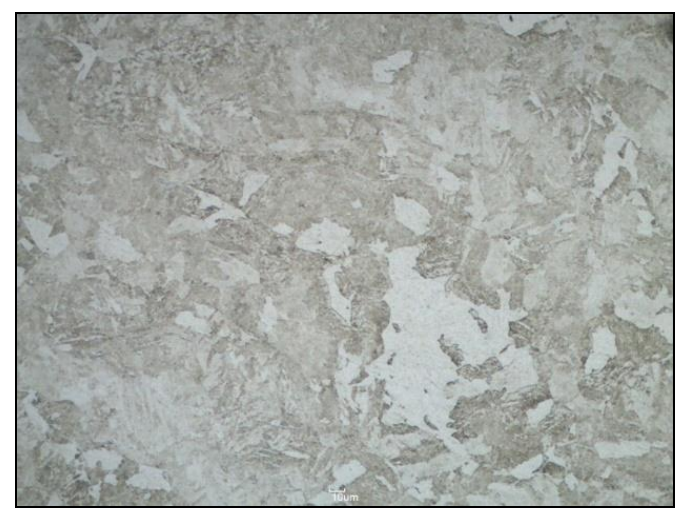

(b)

Fig. 7. AISI 4340 Steel bonified, after welding reparation process, microetching with nital 3\%, 500X, ferritic structure (clear tone) and pearlitic structure (dark tone) (a) $6 \mathrm{~mm}$, (b) $8 \mathrm{~mm}$.

Under standard ASTM E18, hardness test were taken, a variation in this parameter was observed, this change was caused by heat exposure during welding process, these are auspicious conditions to nucleation of cracks, and this affectation produces a ferritic pearlitic structures, which are typical for hypoeutectoid steels[6], table 2 shows reduction in hardness in specific areas of interest.

\begin{tabular}{c|lcc}
\hline \multicolumn{2}{c}{ Data taken area } & Rockwell C & Average \\
\hline \multirow{2}{*}{$\begin{array}{c}\text { Shaft with } \\
\text { original } \\
\text { condition }\end{array}$} & Lenghtwise section & $36,37,36$ & 36.33 \\
\cline { 2 - 4 } & Transversal section & $36,37,37$ & 36.66 \\
\hline \multirow{2}{*}{$\begin{array}{c}\text { Shaft with } \\
\text { welding process } \\
\text { applied }\end{array}$} & Lengthwise section & $\begin{array}{c}28,28,27,30,30,30,30, \\
31,32,31.5,34,35,34,33\end{array}$ & 28.54 \\
\cline { 2 - 4 } & Transversal section & $\begin{array}{c}28,30,31,30,31,32, \\
32,32,33,34\end{array}$ & 31.33 \\
\hline
\end{tabular}

Table 2. Comparison values of hardness variation in areas of interest.

Conclusions. Failure mode in shaft was characterized by a reparation for welding process, due to premature wear on the hexagonal peripheral zone, this reparation persecuted to recover the support area to helical sections, after intervention, was evidenced a nucleation of crack, and propagation of fissure, that led to breaking off the shaft.

The strains analysis was realized for the main drive shaft with hexagonal section, used by to pressing bunches palm oil. To establish boundary conditions was realized a static analysis of loads using like reference the energy consumption, after was reviewed in detail contact conditions, the geometrical shape origins singularity points of stress (specifically hexagonal peripheral borders), to can analyzed high gradients of stress was necessary refining mesh in this area. Numerical results indicate that in these points a yield deformation is reached on these points, this causing plastic deformations and final failure of element. 
Maximum strength found was 823 (MPa), which overpass elastic limit for material of shaft 710 (MPa), indicates that this cause to lose original shape.

Catastrophic fracture on shaft occurs after welding process and it can be attributed to lose of resistance on repaired area. This was originate by heat affected zone (typical term in welding process), it led to nucleation of cracks and propagation of fissure.

\section{References.}

[1] "Entorno económico y desempeño del sector palmero en 2016 y perspectivas 2017."

[2] E. E. Y. Federación Nacional de Cultivadores de Palma de Aceite., J. A. G. Centro de Investigación en Palma de Aceite., and L. E. F. P., Palmas., vol. 21, no. especial,. FEDEPALMA, 2000.

[3] H. K. Jorgensen, "Treatment of empty fruit bunches for recovery of residual oil and additional steam production," J. Am. Oil Chem. Soc., vol. 62, no. 2, pp. 282-286, Feb. 1985.

[4] and D. F. M. F. P. Beer, J. E. Russell Johnston, J. T. DeWolf, Mechanics of Materials. 2015.

[5] T. D. Canonsburg, "ANSYS Workbench Verification Manual,” Knowl. Creat. Diffus. Util., vol. 15317, no. October, pp. 724-746, 2012.

[6] Boyer, E. B. "Failure Analysis and Prevention, Metal Handbook." American Society for Metals, Ohia (1975). 